\section{Beech bark disease and archaeological crop marks}

THE presence of 'crop marks' in aerial photographs is frequently used to detect archaeological features. These marks are produced by differences in plant size or colour which are related to the characteristics of the soil overlying or comprising the man-made feature. Pure stands of many arable crop species are known to show visible responses to soil heterogeneity. In the case of woody perennials we have found only one report describing the detection of archaeological structures by virtue of their influence on the growth of a crop ${ }^{1}$. This was the identification of ancient hut sites in Kenyan tea plantations where excess lime caused failure of the crop. We now report the detection of an ancient field system by virtue of its present-day relationship to patterns of a disorder in beech (Fagus sylvatica L.).

An aerial photograph of pure beech stands planted between 1920 and 1948 at Marden Forest, West Sussex, UK, shows some intriguing 'geometrical' patterns of chlorosis. In the area shown in Fig. 1 the trees were $25 \mathrm{yr}$ old when the photograph was taken in 1973. A ground survey of this area revealed a series of scarps up to $1.4 \mathrm{~m}$ in height on gently sloping ground. The distribution of these scarps and their structure, as revealed by excavation of two of them, suggests that they are the remains of a field system of prehistoric or Romano-British origin. We have surveyed these scarps or lynchets, and Fig. 2 shows their relationship to the pattern of chlorosis plotted by photogrammetric techniques. Most of the affected trees seem to occur immediately below the scarps.

Our original purpose in examining the photograph had been to detect spatial patterns of beech bark disease which is present at this site and is caused by the scale insect Cryptococcus fagi Bär. and the fungus Nectria coccinea (Pers. ex Fr.) Fries. Like many plant diseases, beech bark disease has been surveyed using aerial photography ${ }^{4}$, the symptom which makes such detection possible being foliar chlorosis ${ }^{3}$. This symptom may, however, be caused by other disorders; in particular, a nutritional deficiency in which beeches growing on thin calcareous soils are unable to absorb iron in adequate quantities ${ }^{2}$.

The natural occurrence of nutrient imbalances in soil would not normally follow a spatial pattern of the type displayed by the chlorotic trees. At this site the soil is underlain by chalk and, in its undisturbed state, it probably included a shallow capping of slightly acid material. It is generally considered that in field systems of the type found here, gradual erosion over many years

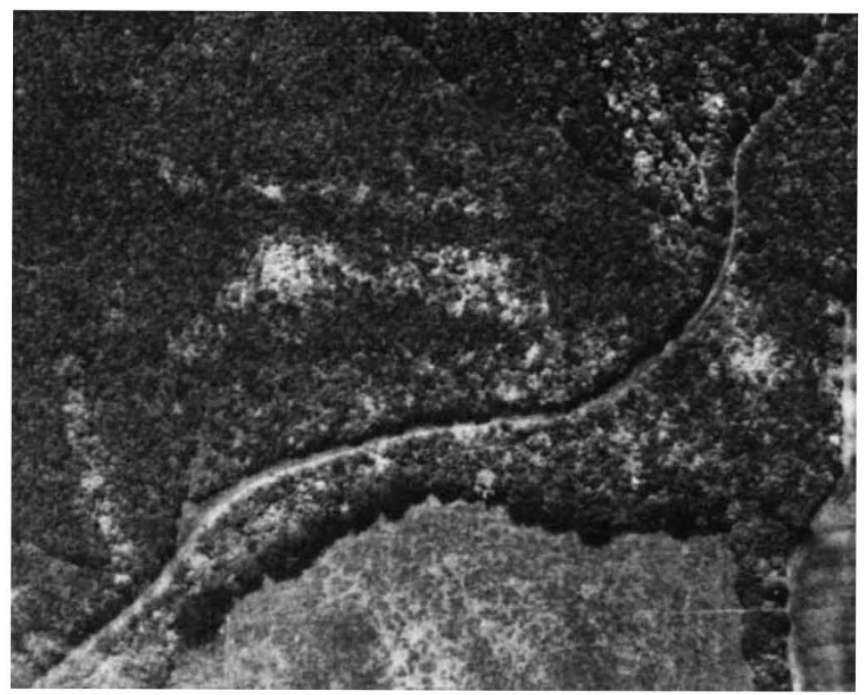

Fig. I Aerial photograph of geometrical patterns of foliar chlorosis at Marden Forest. (Crown copyright reserved.)

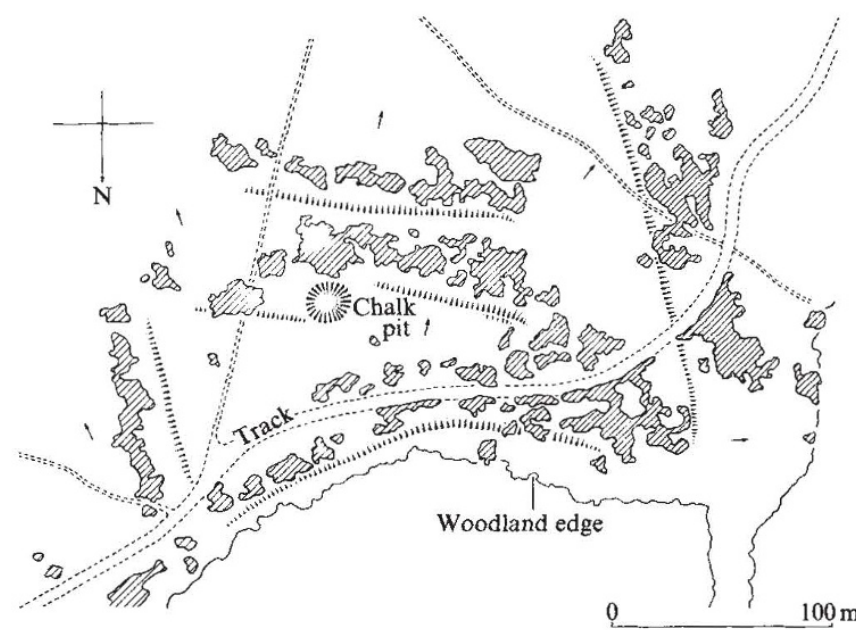

Fig. 2 Map of ancient field system and associated areas of foliar chlorosis. Hachures represent scarps (field boundaries). Crosshatching represents chlorosis. The arrows indicate the direction of the down-slope.

of ploughing along the contour has removed soil from the areas below the field boundaries. Apparently this process, together with disturbance of the underlying chalk, has produced a soil alkaline to the surface so that conditions conducive to nutritional chlorosis have arisen very locally and in a geometrical pattern.

Aerial detection of beech bark disease in areas where nutritional chlorosis is present would seem to be very difficult, although Parker ${ }^{5}$ reported that, in the chalk downland plantations examined during his study of beech bark disease, chlorosis was not due to nutritional causes. Furthermore, there may be interactions between nutritional factors and beech bark disease. Soil factors could affect the susceptibility of the trees to the disease, quite apart from the confusion arising from the production of chlorosis by one or both of the disorders. It would be useful to study the incidence of beech bark disease and of nutritional chlorosis in an area where their spatial patterns are superimposed but can be mapped separately. We believe that the abrupt changes in soil type at the Sussex site offer such an opportunity and we are now surveying in detail the soil variation and the incidence of beech bark disease in the chlorotic and non-chlorotic zones.

The detection of this field system through observing chlorotic tree crowns suggests that the presence of woodland on a site of possible archaeological interest may be less of an obstacle to aerial survey work than has been generally supposed. As far as the detection and prediction of disorders in tree crops are concerned, our findings suggest that knowledge of the ways in which a soil has been modified by man's activities is important to the plant pathologist as well as to those who are responsible for establishing and managing plantations.

We thank Mr H. C. Bowen, of the Royal Commission on Historical Monuments, for discussions.

D. LONSDALE

Forest Research Station,

J. E. PRATT

Alice Holt Lodge,

Wrecclesham, Farnham, Surrey, UK

County Hall,

Tower Street,

Chichester.

Sussex, UK

Received 19 October; accepted 13 Dećember 1978.

1. Bradford, J. Ancient Landscapes: Studies in Field Archaeology (Bell, London, 1957).

2. Day, W. R. Q. Jl For. 40, 72-86 (1946).

3. Ehrlich, J. Can. J. Res. 10 (spec. no.) 593-692 (1934).

4. Houston, D. R. in Pl. Sci. Workshop Proc., Gainsville, Florida, 76-77 (1970)

5. Parker, E. J. thesis, Univ. Surrey (1974). 